\title{
Analysis of User Acceptance of ERP System on After Sales Function Using Unified Theory of Acceptance and Use of Technology (UTAUT) Model
}

\author{
Verina Risky Andwika ${ }^{1}$, R. Wahjoe Witjaksono ${ }^{2}$, Anik Hanifatul Azizah ${ }^{3}$ \\ ${ }^{1,2}$ Department of Information System, School of Industrial and System Engineering, Telkom University \\ ${ }^{2}$ Faculty of Computer Science, Esa Unggul University
}

\begin{tabular}{l} 
Article Info \\
\hline Article history: \\
Received Feb 19, 2020 \\
Revised Mar 02, 2020 \\
Accepted Mar 26, 2020 \\
\hline
\end{tabular}

Keywords:

Enterprise Resource Planning After Sales Function

UTAUT

User Acceptance

Partial Least Square (PLS)

\begin{abstract}
Unified Theory of Acceptance and Use of Technology (UTAUT) is a model used to describe user behavior towards the acceptance of information technology. UTAUT is a development of eight previous leading theories. UTAUT has four constructs that can be a significant direct determinant of behavioral intention and use behavioral, ie performance expectancy, effort expectancy, social influence, and facilitating conditions. This model is then used to analyze user acceptance of Enterprise Resource Planning (ERP) at PT Wijaya Toyota Dago. ERP is a system that can help companies to integrate one process with another process, in order to achieve company goals. This research will explain about the relation of factors influencing acceptance and usage of ERP by using UTAUT model. This research is an explanative research with data analysis technique using PLS (Partial Least Square). Data obtained comes from respondents who are employees of After Sales function of PT Wijaya Toyota Dago, data obtained by way of distributing the questionnaire tertuup. The sample size in this study was 37 resondents and analyzed using SPSS and SmartPLS applications. The analysis results are as follows: (1) Variable Performance Expectancy (PE) has a positive and significant influence on Behavioral Intention (BI); (2) Variable Effort Expectancy (EE) has a positive and significant influence on Behavioral Intention (BI);(3) Social Influence Variables (SI) have a positive and significant influence on Behavioral Intention (BI); (4) Variable Facilitating Conditions (FC) has a positive and significant influence on Use Behavior; (5) Social Influence (SI) variable has positive but not significant influence on Behavioral Intention (BI).
\end{abstract}

This is an open access article under the CC BY-SA license.

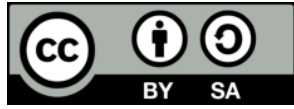

\section{Corresponding Author:}

Verina Risky Andwika,

Department of Information System,

School of Industrial and System Engineering,

Telkom University

Email: verina.risky@gmail.com

\section{INTRODUCTION}

The development of information technology is now increasingly rapid, this is marked by the increasingly frequent companies or agencies to use and implement it to support the company's business processes. One of the factors that can be used to measure the success of the application of information technology in a company is Human Resources (HR) [1], [2]. Measuring the success rate of the application of information technology based on human resource factors or user factors 
can be seen from their behavior, whether to accept or reject the application of information technology [3].

One company that has implemented and utilized information technology is PT Wijaya Toyota Dago. PT Wijaya Toyota Dago is an official dealer of PT Toyota Astra Motor in West Java. One of the functions of companies that implement information technology is the After Sales function. The information technology currently used to regulate spare parts availability is the Toyota Dealer Management System (TDMS). Toyota Dealer Management System or more commonly called TDMS is an internal system owned by Toyota to facilitate the company's operations in serving customer needs. TDMS is a subsystem of SAP (System Application and Product in data processing) which is one of the Enterprise Resource Planning (ERP) software.

According to O'Brien \& Marakas [4] Enterprise Resource Planning is software that is used to reengineer, automate, and integrate the manufacturing, distribution, financial, and human resources business processes in the company. Enterprise Resource Planning (ERP) functions as an integrated cross-functional corporate backbone and can optimize many internal business processes and information systems in the manufacturing, logistics, distribution, accounting, financial, and human resources functions of a company [5].

According to Shin \& Kim [6], the effect of successful application of technology tends to be on the behavioral aspects of its users. New technology is said to be successful if it can be accepted by its users. The TDMS system has been used for approximately 4 years by PT Wijaya Toyota. During its use it is not yet known whether the TDMS system has been accepted by its users because it can increase employee work effectiveness. From the results of observations and interviews conducted with employees of the After Sales function, it is known that by using the TDMS system employees can make purchase orders (PO) spare parts that are directly connected to the Bandung depot, make PKB (Workshop Work Orders), make sales orders, and make invoices for customers. All information in the TDMS system is updated in real-time, thereby reducing human errors. However, in the TDMS system there is still no minimum stock for spare parts, so checking the availability of raw materials is still done manually. Because there is not yet a minimum stock of spare parts in the TDMS system, it is difficult to do forcasting or material forecasting so there is no shortage of spare parts.

One model framework that can be used to measure the level of acceptance of PT Wijaya Toyota Dago employees on the use of oyota Dealer Management System (TDMS) is the Unified Theory of Acceptance and Use of Technology (UTAUT) model. UTAUT is a model developed by Venkatesh et al. in [7]. According to Venkatesh et al. [7], a person's acceptance of information technology (user acceptance) is influenced by four factors namely, Performance Expectancy, Effort Expectancy, Social Influence, and Facilitating Conditions. UTAUT aims to explain the level of user acceptance and user behavior in using information technology.

Based on the problems described above, a study was conducted to analyze the level of acceptance of PT Wijaya Toyota Dago employees with the UTAUT model in applying and utilizing TDMS. The results of the analysis will be given to the head of the workshop to find out what factors influence user acceptance so they can consider these factors for further system development.

\section{LITERATURE REVIEW}

\subsection{Enterprise Resource Planning}

The definition of EPR according to experts is as follows:

1. Enterprise Resource Planning (ERP) is a system that can help manage integrated business processes in a unity such as marketing, production, purchasing and accounting, and can help store all transactions in a database that is used by companies and provide management reporting tools [8].

2. Enterprise Resource Planning (ERP) is a concept of planning and managing company resources, in the form of an integrated and multi-module application package designed to serve and support various functions within the company (to serve and support multiple business functions), so work becomes more efficient and can provide better services for

Analysis of User Acceptance of ERP System on After Sales Function Using ... (Verina Risky Andwika) 
consumers, which ultimately can produce added value and provide maximum benefits for all parties who have an interest (stakeholders) over the company [9].

From the definitions of the experts it can be concluded that Enterprise Resource Planning (ERP) is a system that can help companies to integrate one process with another process, in order to achieve company goals.

\subsection{Unified Theory of Acceptance and Use of Technology (UTAUT)}

Acceptance models (analytical frameworks) are created to help define and understand what factors influence whether or not an innovation is used. The Unified Theory of Acceptance and Use of Technology (UTAUT) is a model used to explain user behavior towards the acceptance of information technology [7].

UTAUT is the development of eight previous leading theories. These theories are Theory of Reasoned Action (TRA), Technology of Planned Behavior (TPB), Technology Acceptance Model (TAM), Motivational Model (MM), combined TAM and TPB, Model of PC Utilization (MPCU), Innovation Diffusion Theory (IDT), and Social Cognitive Theory (SCT) [10].

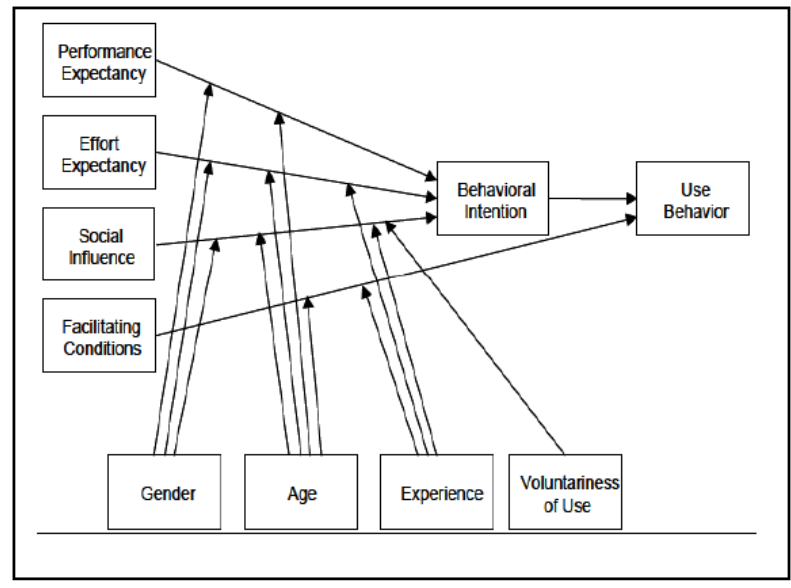

Figure 1. UTAUT Model [7]

The following is an explanation of the four main constructs in UTAUT according to Venkatesh, et al. [7]:

1. Performance expectancy: a person's level of trust in the use of the system will help him to improve work performance. In this concept there is a combination of variables obtained from previous research models about the acceptance and use of technology.

2. Effort expectancy: is the level of ease in using a system that can reduce the energy and time needed to do work. This construct is taken from 3 previous theories, namely, the construct of perceived easy of use from TAM, the complexity of the construct of MPCU, and the construct of easy of use from IDT.

3. Social influence (social influence): is the level where a person feels important people in his life believe that it should use a new system. Social influence is one of the determinants of behavioral goals in using information technology. The construct of social influence is taken from the construct of social factors in MPCU, the construct of image in IDT and the subjective norm construct in TRA, TPB, TAM and C-TAM-TPB.

4. Facilitating condition: is the level of a person's confidence in the availability of technical and organizational infrastructure in supporting the use of a new system. The facilitating condition construct is taken from the construct of perceived behavioral control in TPB, the construct of facilitating conditions in MPCU, and the construct of compability in IDT. 


\section{RESEARCH METHOD}

The research model developed in this study is to use UTAUT. This study aims to determine the level of acceptance of ERP system users at PT Wijaya Toyota Dago.

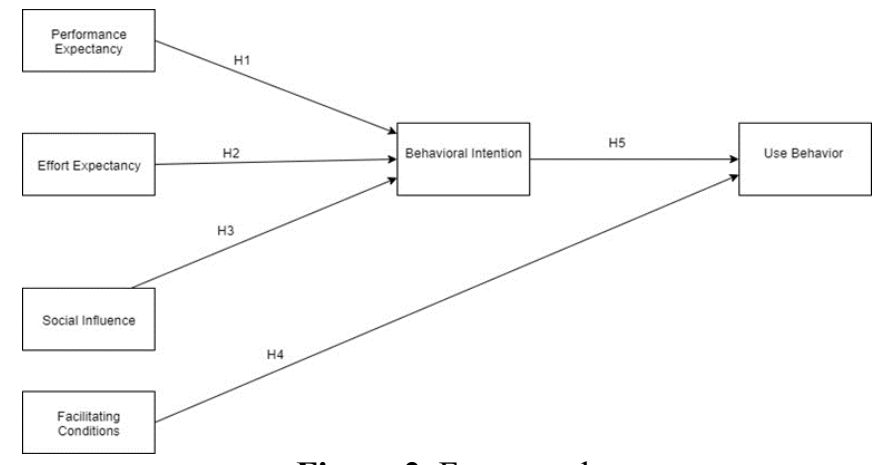

Figure 2. Framework follows:

Based on the research framework in Figure 2, the hypotheses developed in this study are as

H1: Performance Expectancy has a positive and significant influence on Behavioral Intention.

H2: Effort Expectancy has a positive and significant effect on Behavioral Intention.

H3: Social Influence has a positive and significant influence on Behavioral Intention.

H4: Facilitating Conditions have a positive and significant effect on Use Behavior.

H5: Behavioral Intention has a positive and significant effect on Use Behavior.

\section{RESULT AND ANALYSIS}

The data collected in this study are primary data used to analyze ERP system user acceptance at PT Wijaya Toyota Dago by using the Unified Theory of Acceptance and use of Technology (UTAUT) research model through the distribution of questionnaires directly (offline) to 37 respondents who are After Sales function employees who use the ERP system.

The results of ERP system user acceptance analysis at PT Wijaya Toyota Dago can be seen as in the following table (Table 1):

Table 1. PE Validity Test Results

\begin{tabular}{|c|c|c|c|}
\hline Item & Corrected Item-Total Correlation & $\mathbf{r}$ tabel & Information \\
\hline PE1 & 0,644 & \multirow{4}{*}{0,3246} & VALID \\
\cline { 1 - 1 } PE2 & 0,490 & VALID \\
\hline PE3 & 0,746 & & VALID \\
\hline PE4 & 0,618 & & VALID \\
\hline
\end{tabular}

Based on Table 1 describes the items that are subject to validation test measurement on the variable performance expectancy (PE). In Table 2 it can be seen that all values of $r$ count are greater than the values of $r$ table, thus it can be concluded that the validation test of performance expectancy (PE) variables is said to be valid.

Table 2. EE Validity Test Results

\begin{tabular}{|c|c|c|c|}
\hline Item & Corrected Item-Total Correlation & r tabel & Information \\
\hline EE1 & 0,662 & \multirow{3}{*}{0,3246} & VALID \\
EE2 & 0,500 & & VALID \\
\hline EE3 & 0,357 & & VALID \\
\hline
\end{tabular}

Based on Table 2, it describes the items that are subject to validation test measurements on the variable effort expectancy (EE).

In Table 2 it can be seen that all values of $r$ count are greater than the values of $r$ table, thus it can be concluded that the effort expectancy (EE) variable validation test is said to be valid. 
Table 3. SI Validity Test Results

\begin{tabular}{|c|c|c|c|}
\hline Item & Corrected Item-Total Correlation & r tabel & Information \\
\hline SI1 & 0,732 & \multirow{3}{*}{0,3246} & VALID \\
\cline { 1 - 1 } SI 2 & 0,693 & & VALID \\
\hline SI3 & 0,556 & VALID \\
\hline
\end{tabular}

Based on Table 3, it explains about the items that are subject to validation test measurements on social influence variables (SI). In Table 3 it can be seen that all $r$ count values are greater than $r$ table values, thus it can be concluded that the validation test of social influence variables (SI) is said to be valid.

Table 4. FC Validity Test Results

\begin{tabular}{|c|c|c|c|}
\hline Item & Corrected Item-Total Correlation & r tabel & Information \\
\hline FC1 & 0,509 & \multirow{3}{*}{0,3246} & VALID \\
\cline { 1 - 1 } FC2 & 0,233 & & NOT VALID \\
\hline FC3 & 0,397 & VALID \\
\hline
\end{tabular}

Based on Table 4 describes the items that are subject to validation test measurements on the facilitating conditions (FC) variable. In Table 4 it can be seen that the calculated $r$ value on FC2 items is smaller than the $\mathrm{r}$ table value, it means that the FC2 item validity test is invalid. If there are invalid results, it cannot proceed to the next calculation. One of the methods taken in order to proceed with the next calculation is by removing questions on invalid items. In this study FC2 items will be deleted in the calculation process. FC items are said to be not very important because the facilitating conditions (FC) variable is already represented by 2 other questions.

Table 5. BI Validity Test Results

\begin{tabular}{|c|c|c|c|}
\hline Item & Corrected Item-Total Correlation & $\mathbf{r}$ tabel & Information \\
\hline BI1 & 0,613 & 0,3246 & VALID \\
\hline
\end{tabular}

Based on Table 5 describes the items that are subject to validation test measurement on the behavioral intention variable (BI). In Table 5 it can be seen that the value of $r$ calculated BI1 is greater than the value of $r$ table, thus it can be concluded that the validation test of behavioral intention $(\mathrm{BI})$ variables is said to be valid.

Table 6. UB Validity Test Results

\begin{tabular}{|c|c|c|c|}
\hline Item & Corrected Item-Total Correlation & $\mathbf{r}$ tabel & Information \\
\hline UB 1 & 0,688 & 0,3246 & VALID \\
\hline
\end{tabular}

Based on Table 6 describes items that are subject to validation test measurements on the variable use behavior (UB). In Table 6 it can be seen that the $r$ count value of BI1 is greater than the $r$ table value, thus it can be concluded that the use behavior (UB) variable validation test is said to be valid.

After testing the validity, the next step is to conduct a reliability test. In this study to conduct reliability testing using the SPSS application and by using the Cronbach's Alpha method. Data is said to be reliable if the value of Cronbach's Alpha is greater or equal to 0.7 [11]-[13].

Table 7. Reliability Test Results

\begin{tabular}{|c|c|c|c|}
\hline Variable & $\begin{array}{l}\text { Cronbach's Alpha } \\
\text { Score }\end{array}$ & $\begin{array}{c}\text { Minimum Cronbach's } \\
\text { Alpha Score }\end{array}$ & Information \\
\hline $\mathrm{PE}$ & 0,87975 & \multirow{6}{*}{0,7} & RELIABLE \\
\hline $\mathrm{EE}$ & 0,88467 & & RELIABLE \\
\hline SI & 0,87967 & & RELIABLE \\
\hline $\mathrm{FC}$ & 0,88700 & & RELIABLE \\
\hline $\mathrm{BI}$ & 0,88000 & & RELIABLE \\
\hline SI & 0,87700 & & RELIABLE \\
\hline
\end{tabular}


Based on Table 7, it can be concluded that the existing data from each variable is reliable and can be used to do further data processing.

Table 8. Descriptive Analysis Results

\begin{tabular}{|c|c|c|c|c|c|c|}
\hline \multicolumn{9}{|c|}{ Descriptive Statistics } \\
\hline \multirow{2}{*}{ Indicator } & Mean & Std. Deviation & \multicolumn{2}{c|}{ Skewness } & \multicolumn{2}{c|}{ Kurtosis } \\
\cline { 2 - 7 } & Statistic & Statistic & Statistic & Std.error & Statistic & Std.error \\
\hline PE1 & 4,03 & 0,440 & 0,149 & 0,388 & 2,789 & 0,759 \\
\hline PE2 & 3,89 & 0,567 & $-0,033$ & 0,388 & 0,260 & 0,759 \\
\hline PE3 & 3,81 & 0,616 & 0,127 & 0,388 & $-0,360$ & 0,759 \\
\hline PE4 & 3,89 & 0,614 & 0,057 & 0,388 & $-0,209$ & 0,759 \\
\hline EE1 & 3,86 & 0,481 & $-0,405$ & 0,388 & 1,181 & 0,759 \\
\hline EE2 & 3,70 & 0,661 & $-0,203$ & 0,388 & 0,170 & 0,759 \\
\hline EE3 & 3,73 & 0,560 & $-0,018$ & 0,388 & $-0,357$ & 0,759 \\
\hline SI1 & 3,95 & 0,405 & $-0,461$ & 0,388 & 3,682 & 0,759 \\
\hline SI2 & 3,84 & 0,646 & $-0,493$ & 0,388 & 1,002 & 0,759 \\
\hline SI3 & 3,59 & 0,644 & $-0,043$ & 0,388 & $-0,084$ & 0,759 \\
\hline FC1 & 3,92 & 0,547 & $-0,065$ & 0,388 & 0,576 & 0,759 \\
\hline FC3 & 3,54 & 0,650 & $-1,122$ & 0,388 & 0,210 & 0,759 \\
\hline BI1 & 3,81 & 0,569 & $-0,020$ & 0,388 & $-0,037$ & 0,759 \\
\hline UB1 & 4,08 & 0,595 & $-0,017$ & 0,388 & 0,009 & 0,759 \\
\hline Valid N & 37 \\
(listwise)
\end{tabular}

Based on Table 8 it can be seen that the mean obtained from the results of descriptive analysis averages close to 4 . From these results it can be interpreted that the average respondent gives the agreed results. In addition, the low standard deviation value indicates that the distribution of data is narrow which means that most respondents' answers are uniform.

The following is a summary of the results of the structural model evaluation in the form of $\mathrm{R} 2$, path coefficients, and t-statistics, from the results of these values the hypotheses will be rejected or accepted.

Table 9. Results of Evaluation of Structural Models

\begin{tabular}{|c|c|c|c|c|}
\hline Path & $\boldsymbol{\beta}$ & T Value & $\mathbf{R}^{2}$ & $\begin{array}{l}\text { Hypothesis } \\
\text { /Supported }\end{array}$ \\
\hline Performance Expectancy $(\mathrm{PE}) \rightarrow$ Behavioral Intention $(\mathrm{BI})$ & 0,441361 & 4,264535 & \multirow{3}{*}{0,435321} & H1/YES \\
\hline Effort Expectancy $(\mathrm{EE}) \rightarrow$ Behavioral Intention $(\mathrm{BI})$ & 0,316600 & 2,006402 & & H2/YES \\
\hline Social Influence (SI) $\rightarrow$ Behavioral Intention (BI) & 0,026090 & 0,111148 & & $\mathrm{H} 3 / \mathrm{NO}$ \\
\hline Facilitating Conditions $(\mathrm{FC}) \rightarrow$ Use Behavior (UB) & 0,495708 & 5,547558 & \multirow{2}{*}{0,5999140} & H4/YES \\
\hline Behavioral Intention (BI) $\rightarrow$ Use Behavior (UB) & 0,443779 & 4,212270 & & H5/YES \\
\hline
\end{tabular}

\section{Effect of PE on BI}

Based on the submission of the first hypothesis it is known that the proposed $\mathrm{H} 1$ can be accepted. The output path coefficient indicates that the t-statistic value for the construct of $\mathrm{PE}$ against $\mathrm{BI}$ is greater than the value of t-table (1.690), which is 4.264 so that the effect given by PE on $\mathrm{BI}$ is proven significant.

The coefficient value of the latent variable PE on the output path coefficient is 0.44 , which means there is a positive influence of $44 \%$ on the BI construct. The higher the benefits obtained by the user, the higher the acceptance and use of a system can be logically perceived the more beneficial a system will be increasingly accepted and used by the user.

\section{Effect of EE on BI}

Based on the submission of the first hypothesis it is known that the proposed $\mathrm{H} 2$ can be accepted. The output path coefficient indicates that the statistical $t$ value for the EE construct 
against $\mathrm{BI}$ is greater than the t-table value (1.690), which is 2.006 so that the effect given by EE to $\mathrm{BI}$ is proven significant.

The coefficient value of the latent variable EE on the output path coefficient is 0.32 , which means there is a positive influence of $32 \%$ on the BI construct. The higher the ease of use of the system, the higher the acceptance and use of a system. Logically it can be perceived as the use of a system will be increasingly accepted and used by users.

\section{The Effect of SI on BI}

Based on the submission of the first hypothesis it is known that the proposed $\mathrm{H} 3$ was actually rejected. The output path coefficient indicates that the statistical $t$ value for the construct of SI to BI is smaller than the value of t-table (1.690), which is 0.111 so that the effect given by SI to $\mathrm{BI}$ is not significant. The value of the SI latent variable coefficient on the output path coefficient is 0.03 , which means there is a positive influence of $3 \%$ on the BI construct.

\section{FC Effect on UB}

Based on the submission of the first hypothesis it is known that the proposed $\mathrm{H} 4$ can be accepted. The output path coefficient indicates that the t-statistic value for the FC construct of UB is greater than the t-table value $(1,690)$, which is 5.547 so that the influence given by FC on UB is proven significant.

The coefficient value of the latent variable FC on the output path coefficient is 0.49 which means there is a positive influence of $49 \%$ on the BI construct. The higher the ease of use of the system, the higher the value of user trust in available organizational and technical infrastructure. Logically it can be perceived that the more complete the facilities that support the use of the system will be increasingly accepted and used by users.

\section{The Effect of BI on UB}

Based on the submission of the first hypothesis it is known that the proposed H5 can be accepted. The output path coefficient indicates that the $t$-statistic value for the BI construct against UB is greater than the t-table value $(1,690)$, which is 4.212 so that the influence given by FC on UB is proven significant.

The coefficient value of the BI variable on the output path coefficient is 0.44 , which means there is a positive influence of $44 \%$ on the construct of UB. The more the user's intention to use the system, the more acceptance and use of the system.

\section{CONCLUSION}

The conclusions obtained from this study are as follows:

1. This study aims to analyze the behavior of user acceptance and use (After Sales function employees) on the ERP system at PT Wijaya Toyota Dago. The model used to determine what factors influence user acceptance of the implementation and utilization of ERP systems in this study is The Unified Theory of Acceptance and Use of Technology (UTAUT). Tests conducted in this study are validation and reliability test, descriptive analysis, normalization test, inner model test, and hypothesis testing.

2. Based on the analysis of the results of research and discussion in the previous section, it can be concluded as follows:

a. The Performance Expectancy (PE) variable has a positive and significant influence on Behavioral Intention (BI).

b. Variable Effort Expectancy (EE) has a positive and significant effect on Behavioral Intention (BI).

c. Social Influence (SI) Variable has a positive and significant influence on Behavioral Intention (BI).

d. Variable Facilitating Conditions (FC) has a positive and significant effect on Use Behavior. 
e. Social Influence (SI) variable has a positive but not significant effect on Behavioral Intention (BI).

\section{REFERENCES}

[1] H. J. Bernardin, J. E. Russell, and H. J. Bernardin, Human resource management: An experiential approach. 1997.

[2] A. K. Yeung and B. Berman, "Adding value through human resources: Reorienting human resource measurement to drive business performance," Hum. Resour. Manage., vol. 36, no. 3, pp. 321-335, Sep. 1997.

[3] D. Gefen and A. Ragowsky, "A Multi-Level Approach to Measuring the Benefits of an Erp System in Manufacturing Firms," https://doi.org/10.1201/1078/44912.22.1.20051201/85735.3, 2006.

[4] J. A. O'Brien and G. M. Marakas, Introduction to information systems. McGraw-Hill/Irwin, 2007.

[5] M. L. Keong, T. Ramayah, S. Kurnia, and L. M. Chiun, "Explaining intention to use an enterprise resource planning (ERP) system: An extension of the UTAUT model," Business Strategy Series, vol. 13, no. 4. Emerald Group Publishing Limited, pp. 173-180, 2012.

[6] D. H. Shin and W. Y. Kim, "Applying the technology acceptance model and flow theory to Cyworld user behavior: Implication of the Web2.0 user acceptance," Cyberpsychology Behav., vol. 11, no. 3, pp. 378-382, Jun. 2008.

[7] V. Venkatesh, M. G. Morris, G. B. Davis, and F. D. Davis, "User acceptance of information technology: Toward a unified view," MIS Q. Manag. Inf. Syst., vol. 27, no. 3, pp. 425-478, Sep. 2003.

[8] E. F. Monk and B. J. Wagner, Concepts in Enterprise Resource Planning. 2013.

[9] F. Robert Jacobs and F. C. "Ted" Weston, "Enterprise resource planning (ERP)-A brief history," $J$. Oper. Manag., vol. 25, no. 2, pp. 357-363, Mar. 2007.

[10] Y. K. Dwivedi, N. P. Rana, H. Chen, and M. D. Williams, "A meta-analysis of the unified theory of acceptance and use of technology (UTAUT)," in IFIP Advances in Information and Communication Technology, 2011, vol. 366, pp. 155-170.

[11] S. Siegel, "Nonparametric Statistics," Am. Stat., vol. 11, no. 3, pp. 13-19, 1957.

[12] A. Field, Discovering statistics using IBM SPSS statistics. 2013.

[13] J. M. Bland and D. G. Altman, "Statistics notes: Cronbach's alpha," BMJ, vol. 314, no. 7080, p. 572, Feb. 1997. 